in the midline, so the risk of C.S.F. fistula formation is minimized where the operative procedure consists of a focus of damage placed centrally in the right and left halves of the gland.

It is sometimes possible to suspect an "empty" sella, particularly when there is a severe degree of gland subsidence, from the fact that the sella appears abnormally expanded in the lateral $x$-ray film of the skull. ${ }^{48} 9$ In their important study of this subject R. H. Caplan and G. D. Dobben ${ }^{7}$ found that, out of a consecutive series of 17 air encephalograms performed to investigate an enlarged sella turcica before proposed pituitary irradiation, five showed substantial amounts of air within the sella. Pituitary function ranged from complete normality to frank hypopituitarism. None of these patients had had a history of past trauma or other disorders of the pituitary area. A sixth patient, who had had previous external irradiation to the pituitary for acromegaly, also showed air extending down from the subarachnoid space into the tumour area.

Several examples of this curious association between an expanded fossa yet sunken pituitary have been reported, and cases were described in early necropsy series. ${ }^{16}$ It is probably very rare, and the pathogenesis is not yet established. G. F. Joplin, ${ }^{10}$ in a study of the radiological appearances of the normal pituitary fossa of 184 apparently normal persons, made a special examination of the four with the largest area on the lateral film of the skull and included two additional "giant fossae." From the findings he proposed that the primary cause of the condition was medial kinking of the carotids, with lateral compression of both the gland and the lateral edges of the waist of the dorsum sellae, with consequent expansion of the gland in the sagittal plane. This gives the fossa an abnormally balloonéd appearance in lateral films of the skull as well as a thin and narrow dorsum sellae. He suspected that subsequently the gland might atrophy, sinking downward in the sella. Recently in a study of 50 normal necropsy specimens, M. S. F. McLachlan and colleagues ${ }^{11}$ again emphasized the compressive effect on pituitary and dorsum by tortuous carotids.

Unfortunately an "empty" sella is not always shown to be expanded in lateral films of the skull, and apart from the rare case of post-partum pituitary necrosis it could not be suspected on any grounds short of an air encephalogram or contrast

1 Busch, W., Virchows Archiv für pathologische Anatomie und Physiologie und für klinische Medizin, 1951, 320, 437.

2 Sunderland, S., Fournal of Anatomy, 1945, 79, 33

Bergland, R. M., Ray, B. S., and Torack, R. M., fournal of Neurosurgery, $1968,28,93$.

- Friedmann, G., and Marguth, F., Zentralblatt für Neurochirurgie, 1961, 21, 33.

s McLachlan, M. S. F., Williams, E. D., Fortt, R. W., and Doyle, F. H.,

British fournal of Radiology, 1968, 41, 323 .
- Sheehan, H. L., and Summers, V. K., Quarterly Fournal of Medicine, 1949, 18, 319.

1 Caplan, R. H., and Dobben, G. D., Archives of Internal Medicine, 1969, 123, 611 .

- Gabriele, O. F., American fournal of Roentgenology, Radium Therapy and Nuclear Medicine, 1968, 104, 168.

Ring, B. A., and Waddington, M., American Fournal of Roentgenology, Radium Therapy and Nuclear Medicine, 1966, 98, 611.

10 Joplin, G. F., "Therapeutic pituitary ablation by needle implantation," Thesis for Ph.D., 1965, University of London, p. 72.

11 McLachlan, M. S. F., Williams, E. D., and Doyle, F. H., British fournal

12 Engels, E. P., American fournal of Roentgenology, Radium Therapy and Nuclear Medicine, 1958, 80, 1001 .

13 Di Chiro, G., An Atlas of Detailed Normal Pneumoencephalographic Anatomy, p. 302. Illinois, Thomas Springfield, 1961.

14 Kaufman, B., Radiology, 1968, 90, 931.

15 Paterson, J. E., Fournal of Neurology, Neurosurgery and Psychiatry, 1948, $11,280$.

16 Robertson, E. G., Pneumoencephalography, p. 230. Illinois, Thomas Springfield, 1957.

17 Lee, W. M., and Adams, J. E., Fournal of Neurosurgery, 1968, 28, 351.

18 Hartog, M., Doyle, F., Fraser, R., and Joplin, G. F., British Medical fournal, 1965, 2, 396. examination being performed ${ }^{12-14}$ for some independent reason.

Thus it would appear that the "empty" sella may be found in a variety of circumstances. It may be seen in conjunction with a radiologically enlarged sella yet without a pituitary tumour; without any sellar abnormality, occurring either in Sheehan's syndrome ${ }^{6}$ or as an isolated phenomenon; and after necrosis of a tumour, either spontaneous ${ }^{15}$ or as a sequel to pituitary irradiation..$^{16-18}$ An example of spontaneous necrosis in a tumour leading to an "empty" sella is described in the case report of Dr. M. I. Drury and his colleagues in this issue of the B.M.F. Its practical importance is in planning procedures for destruction of the pituitary and in the differential diagnosis of causes of an expanded sella turcica.

\section{When Should Digitalis Be Stopped?}

Digitalis is one of the most useful drugs we have, but the margin between therapeutic benefit and toxicity is small. The digitalis glycosides, especially when combined with potassium-depleting diuretics, are among the most frequently mentioned drugs in surveys of adverse reactions.

There are two main indications for the therapeutic use of digitalis, its positive inotropic action in the failing heartthat is, increasing the force of the heart beat-and the control of heart rate in patients with atrial fibrillation. Oral diuretics have greatly simplified the management of chronic heart failure, and many patients can be kept free of oedema with them alone. In patients with heart failure treatment is usually begun with both digitalis and an oral diuretic. Once the oedema has cleared and the jugular venous pressure has subsided it may be difficult to decide whether either or both drugs are still required.

There is no serious rival to digitalis for the control of atrial fibrillation. Unless the cause of atrial fibrillation can be removed it is usually more satisfactory to employ maintenance digitalis therapy than to attempt defibrillation with direct-current shock.

As digitalis is such a common cause of adverse reactions it is important to consider how they can be avoided and whether the drug can safely be stopped. One obvious answer to the last question is when there was no good reason for prescribing it in the first place. In this week's B.M.F. Dr. J. L. C. Dall discusses the withdrawal of digitalis treatment from 80 geriatric patients under his care. He points out that tachycardia, most probably due to anaemia, and oedema, which in many cases had a local cause such as varicose veins, were common reasons for inappropriate prescription of digitalis. The diuretic action of the drug is evident only in patients with congestive heart failure, and its use to control heart rate is undesirable in patients with a physiological sinus tachycardia. Dr. Dall was able to withdraw maintenance digoxin treatment successfully in $\mathbf{4 8}$ out of 53 patients.

The withdrawal of digitalis from patients who were once in heart failure is more difficult to justify. If the predisposing factor has been removed, as it might have been after a successful mitral valvotomy or reduction of blood pressure in a patient with hypertensive heart failure, it would be worthwhile trying to withdraw it. However, it would be unwise to withdraw digitalis in a patient with a history of heart failure simply because he was free of oedema and had a normal jugular venous pressure at the time. Diuretics remove oedema and lower venous pressure. This can have a beneficial effect on the heart by reducing tricuspid incompetence and raising 
the arterial oxygen tension by removing interstitial oedema in the lung. But diuretics do not increase the force of cardiac contraction, and this action of digitalis is of paramount importance in patients with chronic heart failure. If such patients develop digitalis toxicity, the drug should be temporarily withdrawn or the dose reduced. If potassium depletion is responsible for digitalis toxicity, the patient should be encouraged to take a diet richer in potassium and receive supplements of potassium chloride.

In some patients with chronic congestive heart failure and a badly damaged heart it is hard to know whether symptoms such as loss of appetite or nausea and coupled ventricular ectopic beats are symptoms of digitalis toxicity or of the disease itself. It is usually possible to answer this question by withdrawing digitalis for a few days. It would be helpful if there were some other method of establishing whether the digitalis or the disease is the more at fault, and recent developments of methods for measuring the plasma concentration of the drug hold out the promise that this may be possible. If the therapeutic and toxic range of the concentration of digitalis in plasma can be clearly established, it should be possible to adjust the dose to achieve the correct level without stopping treatment.

\section{Psychiatric Symptoms of Cancer}

One hundred years ago most psychiatrists would have agreed that physical causes of mental ills would be revealed by progress in medical science. They therefore contented themselves with describing rather than classifying patients, and aiding spontaneous recovery, while they devoted much of their research to neuropathology - the only fruitful line of biological investigation open to them-to which they made fundamental contributions.

Then in the last decade of the 19th century Kraepelin attempted to delineate mental diseases by a crude correlation of symptoms with outcome. ${ }^{1}$ Search for causes took second place to disputes:about classification and the differentiation of "neurosis" from "psychosis" and "thought disorder" from "affective disorder." Opposition to the new psychiatry-bydefinition faded some ten years later when Bleuler elaborated and reinforced Kraepelin's teaching by applying to it the psychodynamic theories of Freud and Jung. ${ }^{2}$ Bleuler's "schizophrenia" concept caught on and with it a general acceptance of "psychosyndromes" as entities in their own right. Though today increasingly recognized as the stumbling block to fundamental progress, ${ }^{3}$ it still dominates psychiatric thinking and is chiefly responsible for the gulf between psychiatry and medicine.

By the time advances in the basic sciences had turned medicine from a descriptive art to an investigative science and neurology was in a position to account for nervous symptoms previously attributed to the mind, psychiatrists were even further isolated by the lure of specific treatments for specific Kraepelinian ills, which promised rich rewards. Against this trend reports continued to appear pointing to the concurrence of gross physical disease with seemingly textbook psychosyndromes. One such is a recent study from Newcastle. ${ }^{4}$

One hundred and twenty-eight patients suffering from affective disorders-anxiety states and depression-were followed up four years after admission to hospital. Of 28 diagnosed as "depressive illness" and treated accordingly, 5 men were found to have died of carcinoma at various sites. Compared with national death rates this incidence was significantly raised. Their ages ranged from 49 to 82 , and none had a previous psychiatric history. Mean survival time from onset of psychiatric symptoms to death was about two and a half years and from psychiatric treatment to death about one year. Professor M. Roth and his colleagues conclude that "a form of depressive illness in male patients arising in late middle age without previous psychiatric illness and occurring without apparent cause may be an early and direct manifestation of latent carcinoma." Presumably latent does not imply that psychiatric symptoms marked a hypothetical precancerous state but that the cancer had not yet shown itself in local symptoms.

That being so, there are a number of possibilities to account for the association. The most obvious is that patients had metastatic lesions of the nervous system which were missed because the lesions were small or in neurologically silent areas. Or they may have had one of the non-metastatic neurological complications which are now well documented, 5 among which dementia is common and depression of mood may be marked. ${ }^{6}$ The spectrum of metabolic disorders now known to be associated with cancer is so wide that in the opinion of some it has replaced syphilis as "the great imitator." ? Patients may have had specific syndromes of this kind, as for instance malabsorption due to carcinoma of the stomach and ingravescent uraemia in the case of the patient who died of prostatic carcinoma within four months of having his depression treated. In such circumstances "depression" may simply reflect how the patient perceives or describes his malaise and lowered vitality, or how his doctor interprets it. Anergy and apathy not infrequently usher in mental or physical failure of any kind. They may mark the early stages of presenile dementias of Pick-Alzheimer type, which occasionally develop at the same time as a carcinoma though their relation is unclear. ${ }^{8}$

These diagnostic possibilities remain speculative. The only laboratory finding mentioned is that two patients had a high sedimentation rate. Physical disease underlying the psychosyndrome was by the authors' own statement not suspected and hence not looked for. As is common in psychiatric practice, lack of signs on routine physical examination was taken to exclude it. But across the whole field of medicine this is no longer enough. Psychiatry, says one distinguished critic, ${ }^{9}$ is neurology without physical (that is predominantly motor) signs "and calls for diagnostic virtuosity of the highest order." Its practice demands an ever-ready awareness of organic disease and first-class laboratory facilities. The psyche is often a more sensitive indicator of disease than the body.

Had the abnormal mental state been evaluated as a sign of disordered bodily function, who knows but that thoroughgoing investigation while patients were still only depressed might have discovered the cancer earlier and while it was still amenable to treatment? Medicine today knows of innumerably more causes of disease leading to mental change than ever Kraepelin could dream of. Professor Roth and his colleagues have added important evidence that the presenting symptom of depression, especially in the older age-groups, calls for rigorous exclusion of organic disease.

1 Kraepelin, E., Psychiatrie, 6th edn., 2 vols. Leipzig, Barth, 1899

- Bleuler, E., Dementia Praecox oder die Gruppe der Schizoprenien. Leipzig, Deuticke, 1911. English translation by J. Zinkin, New York, International Universities Press, 1950.

3 Redlich, F. C., and Freedman, D. X., The Theory and Practice of Psychiatry. New York, Basic Books, 1966.

4 Kerr, T. A., Schapira, K., and Roth, M., British fournal of Psychiatry, $1969,115,1277$.

5 Brain, W. R., and Norris, F. H., (eds.), The Remote Effects of Cancer on the Nervous System. New York, Grune and Stratton, 1965.

- Brain, W. R., Lancet, 1963, 1, 179 .

7 Holland, J. F., Fournal of Chronic Diseases, 1963, 16, 635.

8 Mansvelt, J. van, Pick's Disease, Enschede, Loeff, 1954.

- Miller, H., British fournal of Hospital Medicine, 1970, 3, 122. 